\title{
Voltammetric Method Using Multi-Walled Carbon Nanotubes Modified Glassy Carbon Electrode for the Determination of Terbutaline Sulfate in Pork Sample
}

\author{
Wei Xu, Rulin Lei, Wenying Cao, Chunhui Guo, Xiuhua Zhang ${ }^{*}$, Shengfu Wang \\ Ministry-of-Education Key Laboratory for the Synthesis and Application of Organic Functional Molecules \& College of Chemistry \\ and Chemical Engineering, Hubei University, Wuhan, China. \\ Email: ${ }^{*}$ zhanganal@yahoo.com.cn
}

Received March 23 ${ }^{\text {rd }}, 2013$; revised April 23 $3^{\text {rd }}, 2013$; accepted May $17^{\text {th }}, 2013$

Copyright (C) 2013 Wei Xu et al. This is an open access article distributed under the Creative Commons Attribution License, which permits unrestricted use, distribution, and reproduction in any medium, provided the original work is properly cited.

\begin{abstract}
Electrochemical properties of terbutaline sulfate (TBS) at the glassy carbon electrode modified with multi-walled carbon nanotubes (MWNTs) were explored by cyclic voltammetry (CV) and differential pulse voltammetry (DPV). The response was evaluated with respect to $\mathrm{pH}$, scan rate and other variables. Some electrochemical parameters, such as the charge number and proton number, were calculated. The results indicated that TBS underwent irreversible oxidation at the modified electrode, which was an adsorption-controlled process with two protons and two electrons. The reductive peak current of TBS significantly increased and the peak potential shifted negatively at the modified electrode, thus resulting in an electrode for TBS. The current was proportional to the concentration of TBS over 1.12 and $141 \mu \mathrm{M}$ with a detection limit of $0.34 \mu \mathrm{M}($ at $\mathrm{S} / \mathrm{N}=3)$. The modified electrode showed good sensitivity, selectivity and stability for the determination of TBS in pork sample.
\end{abstract}

Keywords: Terbutaline Sulfate; Multi-Walled Carbon Nanotubes; $\beta_{2}$-Agonist; Electro-Oxidation

\section{Introduction}

Terbutaline sulfate (TBS), $\beta$-[(tert-butylamino) methyl]3,5-dihydroxy-benzyl alcohol $\left(\mathrm{C}_{12} \mathrm{H}_{19} \mathrm{NO}_{3}\right)$, is a $\beta_{2}$-agonist that is widely used as a bronchodilator in acute and long-term treatment of chronic bronchitis, emphysema and other chronic obstructive pulmonary diseases [1]. In the livestock industry, TBS has been used as growth promoters. Researchers showed that it could increase muscle mass, and improve growth rate and feed conversion when fed to animals [2,3]. However, the drug residues in animal tissues may pose a potential risk, such as muscular tremors, vomiting, nervousness, and cardiac palpitations. Therefore, the determination of such drug is important for quality assurance in pharmaceutical preparations and level assay in biological fluids.

Various analytical methods have been developed for the determination of TBS, including spectrophotometry [4], chemiluminescence [5], liquid chromatography [6], and immunoassay with polyclonal or monoclonal antibodies [7]. However, spectrophotometry and chemilu-

\footnotetext{
Corresponding author.
}

minescence usually require complex sample pre-treatments, which can be laborious and time-consuming, due to the interference caused by the compounds that are frequently found along with TBS in pharmaceutical preparations and biological fluids. Liquid chromatography is time-consuming and may lead to variability in the results [8]. Cost must be considered when determining TBS with immunoassay. Therefore, an alternative analytical method which is rapid, cheap and convenience is urgently required.

Electrochemical methods have many advantages such as short run time, instrumentation simplicity and minimum operation cost. They have been proven to be the preferred techniques for the analysis of $\beta_{2}$-agonists, because most of the $\beta_{2}$-agonists can be oxidized at bare or modified electrodes. Voltammetric methods based on nafion modified electrodes $[9,10]$, carbon nanotubes modified electrodes [11,12], imprinted polymer-modified electrodes [13], and $C_{60}$ modified electrodes [14] have been developed for the determination of clenbuterol and salbutamol, which also belong to $\beta_{2}$-agonists drug. However, very litter work has been performed on the determination 
of TBS by the direct electrochemical measurement with the solid-electrodes. Yilmaz et al. [15] have investigated the oxidation of terbutaline at an activated naked glassy carbon electrode, and a relativity weak peak current at about $0.8 \mathrm{~V}$ was aroused. Shen et al. have evaluated the voltammetric characteristics of several $\beta_{2}$-agonists drug using graphite nanosheet modified GCE. They signed with only a cursory glance at TBS in their report.

Since the discovery of multi-walled carbon nanotubes (MWNTs) by Iijima in 1991 using transmission electron microscopy [16], MWNTs-modified electrode has attracted enormous interest. The interest is due to their unique chemical, electronic, mechanical and structural properties, which differ greatly from those of the bulk material. There are four main advantages for a nanotubemodified electrode compared with a macroelectrode [17, 18]. The large effective surface area affords a large number of active sites. The small dimensions of nanoparticles result in a high rate of mass transport to the electrode surface. The catalytic properties of some nanotubes can cause a decrease in the overpotential [19]. MWNTs have relatively high electrical conductivity due to the outer shell which is usually much larger in diameter than SWNTs [20]. Present work is focused on MWCN due to their high electrical conductivity and low price as compared to SWNTs.

In the present paper, MWNTs-GCE was prepared and used for investigating the electrochemical properties of TBS. To the best of our knowledge, a systematic study of the electro-oxidation behaviors of TBS at modified electrode has not been reported so far.

\section{Experimental}

\subsection{Reagents and Apparatus}

TBS was purchased from Shanghai Boyun Biotech. Co. Ltd (Shanghai, China) and used as received. MWNTs ( $95 \%$ purity) with an average diameter of $30 \mathrm{~nm}$ were purchased from Chengdu Organic chemicals Co. Ltd. (Chengdu, China), Chinese Academy of Sciences. Phosphate buffer (PBS) was comprised with $\mathrm{Na}_{2} \mathrm{HPO}_{4}$ and $\mathrm{NaH}_{2} \mathrm{PO}_{4}$. The $\mathrm{pH}$ value was adjusted with $\mathrm{NaOH}$ and $\mathrm{H}_{3} \mathrm{PO}_{4}$. All other chemicals were of analytical-regent grade. All solutions were prepared with double-distilled water.

Electrochemical measurements were performed by a model CHI 630A electrochemical workstation $(\mathrm{CH}$ Instruments, Chenhua Co., Shanghai, China) controlled by a personal computer. A standard three-electrode system was used comprising a MWNTs-GCE as the working electrode, a saturated calomel electrode (SCE) as the reference electrode and a platinum wire as the auxiliary electrode. All the following potentials reported in this work are against SCE. Unless otherwise stated, measurements were carried out in PBS $(0.1 \mathrm{M}, \mathrm{pH}$ 6.0). The $\mathrm{pH}$ value of electrolyte was determined by using a pHS25 acidity meter (Weiye, Shanghai). The data were obtained at room temperature.

\subsection{Preparation of MWNTs-GCE}

MWNTs crude materials were agitated in an ultrasonic bath with $3 \mathrm{M}$ nitric acid for 1 hour. Then it was refluxed in $5 \mathrm{M} \mathrm{HCl}$ solution for $4 \mathrm{~h}$ at $110^{\circ} \mathrm{C}$. After acid treatment, MWNTs were calcined in static air for $2 \mathrm{~h}$ at $350^{\circ} \mathrm{C}$. Here, 0.5 milligram of purified MWNTs was dispersed in $1 \mathrm{~mL}$ of SDS solution $(0.5 \mathrm{mM})$ and the mixture was agitated in an ultrasonic bath to achieve a welldispersed suspension. A cleaned GCE was coated by casting $15 \mu \mathrm{L}$ of the black suspension of MWNTs-SDS and dried in the air for $8 \mathrm{~h}$ to remove the solvent. Then MWNTs modified GCE was prepared. The surface areas of the bare GCE and MWNTs-GCE calculated to be $0.0598 \mathrm{~cm}^{2}$ and $0.6236 \mathrm{~cm}^{2}$, respectively [21]. Obviously, the MWNTs modified electrode increased by nearly 10 times in area.

\section{Results and Discussion}

\subsection{Cyclic Voltammetric Behavior of TBS at the MWNTs/GCE}

Cyclic voltammograms (CVs) of TBS in $0.1 \mathrm{M}$ PBS (pH 6.0) at MWNTs-GCE and bare GCE were shown in Figure 1. At the GCE (Figure 1(b)), a weak oxidative peak at about $0.86 \mathrm{~V}$ can be observed in the presence of TBS. In comparison with GCE, at the MWNTs-GCE (Figure 1(d)), the oxidative peak current increased greatly with the peak potential shifted negatively to $0.71 \mathrm{~V}$. The oxidative peak current at MWNTs/GCE was obvious larger

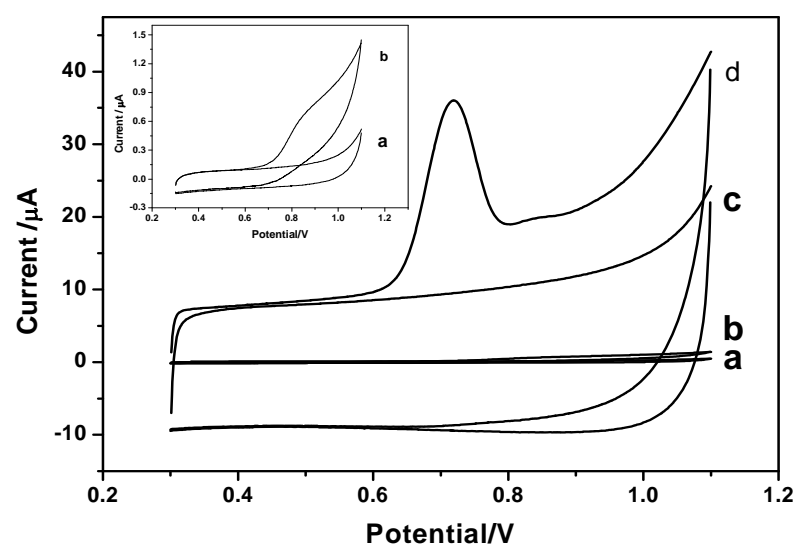

Figure 1. CVs at a bare GCE $(a, b)$ and a MWNTs-GCE (c, d) in the absence (a and c) and in the presence (b and d) of $4.60 \times 10^{-5} \mathrm{M}$ TBS in $0.1 \mathrm{M}$ PBS $(\mathrm{pH}=6.0)$. Scan rate: 0.1 $\mathrm{Vs}^{-1}$. Inset: the magnitude of $(\mathrm{a}, \mathrm{b})$. 
than that at bare GCE. The increase in the peak current and negative shift of the peak potential at MWNTs-GCE suggested that the carbon nanotubes has excellent electrocatalytic effect on the oxidation of TBS and must provide a suitable environment for the TBS to transfer electrons with underlying $\mathrm{GC}$ electrode. The excellent electrocatalytic activity for the CNT-modified electrodes may be due to the unique properties of CNTs, such as high specific surface area, subtle electronic properties, the presence of the functional groups and appropriate pore structures $[22,23]$. There was no electrochemical response at the modified electrode in the absence of TBS (Figure 1(c)), suggesting that the peak at $0.71 \mathrm{~V}$ was ascribed to the oxidation of TBS. The background current became larger, which was attributed to the fact that MWNT could increase the surface activity markedly. Only oxidation peak was observed, which proved that the oxidation process was a totally irreversible electrode process. For a irreversible system, $\left|E_{\mathrm{p}}-E_{\mathrm{p} / 2}\right|=47.7 / \mathrm{\alpha n}$, where $E_{\mathrm{p}}$ refers to peak potential, $\mathrm{E}_{\mathrm{p} / 2}$ half-wave potential, $\alpha$ charge transfer coefficient, the electron transfer number (n) of reduction step can be calculated to be about 2 .

\subsection{Effect of Scan Rate}

The influence of scan rate on the oxidation of TBS at MWNTs-GCE was studied by CV. The peak current was proportional to the scan rate in the range $50-500 \mathrm{mV} \cdot \mathrm{s}^{-1}$ (as shown in Figure 2 and the inset plot), the regression equations were as follow: $i_{\mathrm{pa}}=6.84 \times 10^{-6} v+2.73 \times$ $10^{-6}\left(i_{\mathrm{pa}}: \mu \mathrm{A}, v: \mathrm{Vs}^{-1}, \mathrm{R}=0.998\right)$. The results suggested that the electrochemical behavior of TBS at MWNTsGCE was an adsorption controlled process.

\subsection{Effect of pH}

The oxidative potential shifted negatively as the $\mathrm{pH}$ increased, indicating that the reaction was accompanied by the proton transfer. The peak current reached its summit at $\mathrm{pH}$ 6.0. So, $\mathrm{pH}$ 6.0 PBS $(0.1 \mathrm{M})$ was employed as the supporting electrolyte. The relationship between the potential and $\mathrm{pH}$ was linear, and the regression equation was as follow: $E_{\mathrm{pa}}(\mathrm{V})=1.076-0.059 \mathrm{pH}$. The slope of the above equation was very close to the anticipated Nernstian value of $59 \mathrm{mV}$ for electrochemical processes involving the same number of protons and electrons [24]. As the electron transfer number of TBS was 2, the proton number intervening with the redox process could also be calculated to be approximately 2 .

\subsection{Effect of Accumulation Potential and Accumulation Time}

The effects of accumulation potential and accumulation time were investigated by differential pulse voltammetry
(DPV) in the presence of $4.6 \times 10^{-5} \mathrm{M}$ TBS from 0.4 to $0.7 \mathrm{~V}$ and 0 to $150 \mathrm{~s}$, respectively. When accumulation potential was $0.5 \mathrm{~V}$ and accumulation time was longer than $120 \mathrm{~s}$, the peak current tended to be constant. So 0.5 $\mathrm{V}$ was chosen as accumulation potential and $120 \mathrm{~s}$ was chosen as accumulation time for subsequent analysis.

\subsection{Analytical Applications}

DPV was employed for the determination of TBS at the MWNTs-GCE because of its higher current sensitivity and better resolution than CV (Figure 3). It was found that the oxidation peak current increased with the concentration of TBS. A calibration curve of I versus $\log \mathrm{c}$ (I $\left.(\mu \mathrm{A})=7.66 \times 10^{-6} \operatorname{logc}(\mathrm{M})+4.61 \times 10^{-5}\right)$ was obtained in the concentration range of $1.12 \mu \mathrm{M}$ to $141 \mu \mathrm{M}$. The

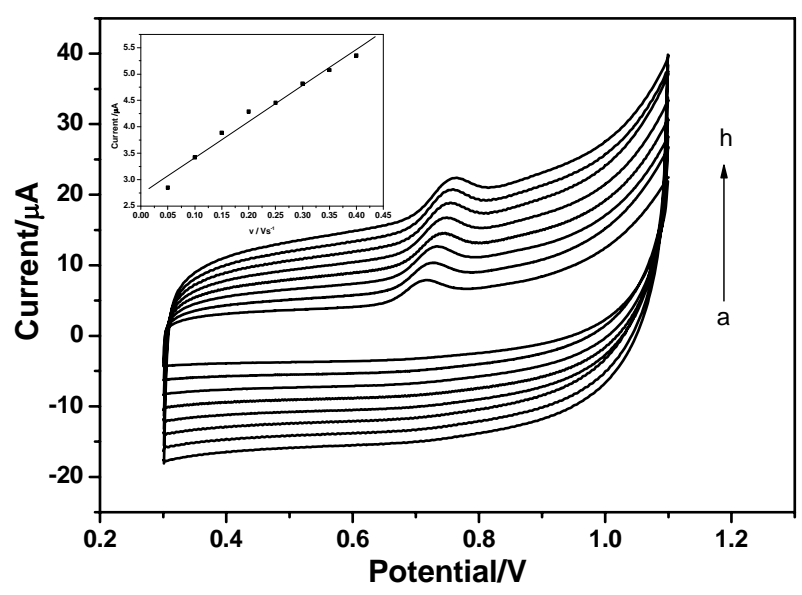

Figure 2. CVs of $1.00 \times 10^{-5} \mathrm{M}$ TBS in $0.1 \mathrm{M}$ PBS $(\mathrm{pH}=6.0)$ at MWCNT-GCE over a range of scan rates $(\mathrm{a} \rightarrow \mathrm{h}: \mathbf{5 0 , 1 0 0 ,}$ $\left.150,200,250,300,350,400 \mathrm{mV} \cdot \mathrm{s}^{-1}\right)$. Inset: The relationship between the peak currents and scan rates.

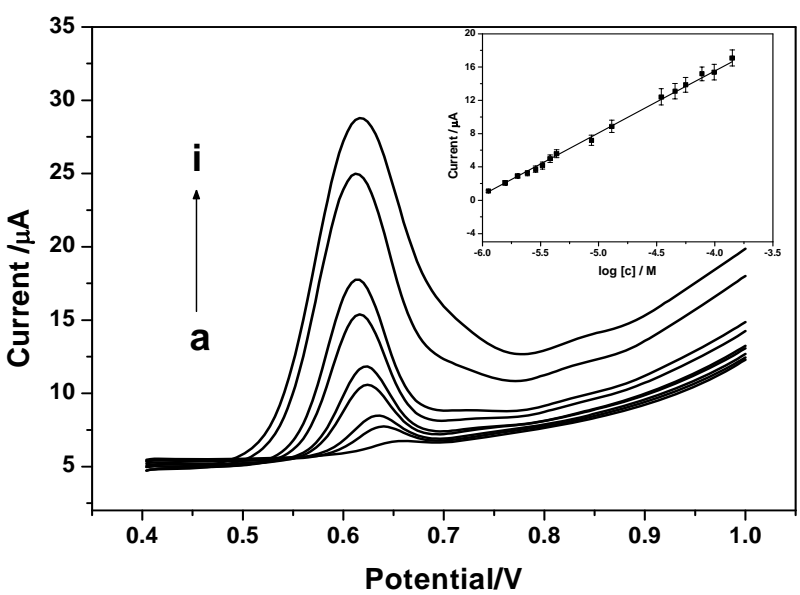

Figure 3. DPVs for TBS present at different concentrations in 0.1M PBS at MWCNT-GCE (a to i): 1.12, 1.57, 2.00, 3.82, 8.67, 23.8, 34.6, 98.7, $141 \mu \mathrm{M}$. Insert: Linear relationship between $I_{p}$ and $\log [c]$ in the range of 1.12 and $141 \mu \mathrm{M}$. 
detection limit (three times the signal blank/slope) is up to $0.34 \mu \mathrm{M}$. The detection limit was lower than the valves of $6 \mu \mathrm{M}$ at the activated GCE.

In order to evaluate the reliability of the proposed method for the determination of TBS, a recovery test was carried out by adding known amounts of a TBS standard to the pork sample. To prepare pork sample, $5.0 \mathrm{~g}$ of shredded pork was set into a polypropylene centrifuge tube and mixed with $10 \mathrm{~mL}$ standard phosphate buffer solution. After the addition of $50 \mu \mathrm{L} \beta$-glucuronidase, it was mixed thoroughly and kept at $37^{\circ} \mathrm{C}$ for $10 \mathrm{~h}$. After and, methanol was added and the mixture was centrifuged at 12,000 rpm for $15 \mathrm{~min}$. Then, the obtained deproteinized pork was diluted to $100.0 \mathrm{~mL}$ by PBS. As shown in Table 1, the recoveries obtained ranged from $94.0 \%$ to $111.3 \%$, indicating that the modified electrode is reliable for the quantification of TBS.

A period of 2 months was subsequently employed to verify the storage stability of the MWNTs-GCE. The electrode was stored in dry state when not in use. It can retain $67 \%$ of the initial signal after 2 months. The relative standard deviation (RSD) of ten successive detections of $10.00 \mu \mathrm{M}$ TBS using one single modified electrode was $1.1 \%$. The RSD of ten detections of $10.00 \mu \mathrm{M}$ TBS by different MWNTs-GCE fabricated independently was $9.6 \%$. These results indicate that the modified electrode has good stability and reproducibility.

Possible interference with the detection of TBS at the MWNTs-SDS-GCE was investigated by adding various ions to PBS in the presence of $10.00 \mu \mathrm{M}$ TBS. Common ions such as $\mathrm{Na}^{+}, \mathrm{Ca}^{2+}, \mathrm{Zn}^{2+}, \mathrm{Fe}^{3+}, \mathrm{Cl}^{-}, \mathrm{SO}_{4}^{2-}$, Glucose at a 1000-fold concentration did not show any interference with a TBS detection. While a 10-fold concentration of ascorbic acid, dopamine or salbutamol produced serious interference.

\section{Conclusion}

MWNTs-GCE was prepared and used for the investigation of the electrochemical properties of TBS. The peak current increased obviously and the peak potential shifted negatively compared with GCE, indicating that MWNTsGCE has excellent electrocatalytic activity for the oxidative reaction of TBS. The electrochemical reaction of

Table 1. Determination of TBS in pork sample.

\begin{tabular}{cccc}
\hline Samples No. & Added $\left(10^{6} c / \mathrm{M}\right)$ & $\begin{array}{c}\text { Found } \pm \text { S.D. }{ }^{\mathrm{a}} \\
\left(10^{6} c / \mathrm{M}\right)\end{array}$ & Recoveries (\%) \\
\hline 1 & 2.5 & $2.35 \pm 0.07$ & 94.0 \\
2 & 5.0 & $5.43 \pm 0.05$ & 91.4 \\
3 & 7.5 & $7.17 \pm 0.08$ & 95.6 \\
\hline
\end{tabular}

${ }^{\mathrm{a}}$ S.D.: standard deviation $(n=3)$.
TBS was a adsorption-controlled process with two protons and two electrons. The MWNTs-GC showed good sensitivity, a low detection limit and reproducibility.

\section{Acknowledgements}

This work was financially supported by the National Natural Science Foundation of China (No. 21075029, No. 20575017), the Program for Excellent Youth Scholars of Innovative Research Team by Hubei Provincial Department of Education (T201101), Hubei Provincial Department of Education (D20113004).

\section{REFERENCES}

[1] N. Daraghmeh, M. M. Al-Omari, Z. Sara, A. A. Badwan and A. M. Jaber, "Determination of TBS and Its Degradation Products in Pharmaceutical Formulations Using LC," Journal of Pharmaceutical and Biomedical Analysis, Vol. 29, 2002, pp. 927-937. doi:10.1016/S0731-7085(02)00216-9

[2] L. Shen, Z. Li and P. He, "Electrochemical Behavior of $\beta_{2}$-Agonists at Graphite Nanosheet Modified Electrodes," Electrochemistry Commuications, Vol. 12, No. 7, 2010, pp. 876-881. doi:10.1016/j.elecom.2010.04.010

[3] N. J. Engeseth, K. O. Lee, W. G. Bergen, W. G. Helferich, B. K. Knudson and R. A. Merkel, "Fatty Acid Profiles of Lipid Depots and Cholesterol Concentration in Muscle Tissue of Finishing Pigs Fed Ractopamine," Journal of Food Science, Vol. 57, No. 5, 1992, pp. 1060-1062. doi:10.1111/j.1365-2621.1992.tb11262.x

[4] S. Agatonovic-Kustrin and R. Alany, "Application of Diffuse Reflectance Infrared Fourier Transform Spectroscopy Combined with Artificial Neural Networks in Analysing Enantiomeric Purity of Terbutaline Sulphate Bulk Drug," Analytica Chimica Acta, Vol. 449, No. 1-2, 2001, pp. 157-165. doi:10.1016/S0003-2670(01)01234-X

[5] Z. P. Wang, Z. J. Zhang, Z. F. Fu, D. L. Chen and X. Zhang, "Flow-Injection Chemiluminescence Detection for Studying Protein Binding of Terbutaline Sulfate with On-Line Microdialysis Sampling," Journal of Pharmaceutical and Biomedical Analysis, Vol. 33, No. 4, 2003, pp. 765-773. doi:10.1016/S0731-7085(03)00416-3

[6] M. P. Turberg, J. M. Rodewald and M. R. Coleman, "Determination of Ractopamine in Monkey Plasma and Swine Serum by High-Performance Liquid Chromatography with Electrochemical Detection," Journal of Chromatography B, Vol. 675, No. 2, 1996, pp. 279-285. doi:10.1016/0378-4347(95)00397-5

[7] W. L. Shelver and D. J. Smith, "Application of a Monoclonal Antibodybased Enzyme-Linked Immunosorbent Assay for the Determination of Ractopamine in Incurred Samples from Food Animals," Journal of Agricultural and Food Chemistry, Vol. 50, No. 10, 2002, pp. 27422747. doi:10.1021/jf011372+

[8] S. Li, J. Wang and S. Zhao, "Determination of TBS by Capillary Electrophoresis with Chemiluminescence De- 
tection," Journal of Chromatography B, Vol. 877, No. 2009, pp. 155-158.

[9] S. Moane, J. R. B. Rodriguez, A. J. M. Ordieres, P. T. Blanco and M. R. Smyth, "Electrochemical Behaviour of Clenbuterol at Nafion-Modified Carbon-Paste Electrodes," Journal of Pharmaceutical and Biomedical Analysis, Vol. 14, No. 1-2, 1995, pp. 57-63. doi:10.1016/0731-7085(95)01610-4

[10] S. Moane, M. R. Smyth and M. O'Keeffe, "Differential-Pulse Voltammetric Determination of Clenbuterol in Bovine Urine Using a Nafion-Modified Carbon Paste Electrode," Analyst, Vol. 121, No. 6, 1996, pp. 779-784. doi:10.1039/an9962100779

[11] R. X. Guo, Q. Xu, D. Y. Wang and X. Y. Hu, "Trace Determination of Clenbuterol with an MWCNT-Nafion Nanocomposite Modified Electrode," Microchimica Acta, Vol. 161, No. 1-2, 2008, pp. 265-272. doi:10.1007/s00604-007-0766-3

[12] C. Karuwan, A. Wisitsoraat, T. Maturos, D. Phokharatkul, A. Sappat, K. Jaruwongrungsee, T. Lomas and A. Tuantranont, "Flow Injection Based Microfluidic Device with Carbon Nanotube Electrode for Rapid Salbutamol Detection," Talanta, Vol. 79, No. 4, 2009, pp. 995-1000. doi:10.1016/j.talanta.2009.02.015

[13] P. Andrea, S. Miroslav, S. Silvia and M. Stanislav, "A Solid Binding Matrix/Molecularly Imprinted PolymerBased Sensor System for the Determination of Clenbuterol in Bovine Liver Using Differential-Pulse Voltammetry," Sensors and Actuators B: Chemical, Vol. 76, 2001, pp. 286-294. doi:10.1016/S0925-4005(01)00586-X

[14] R. N. Goyal, D. Kaur, S. P. Singh and A. K. Pandey, "Effect of Graphite and Metallic Impurities of $\mathrm{C}_{60}$ Fullerene on Determination of Salbutamol in Biological Fluids," Talanta, Vol. 75, 2008, pp. 63-69. doi:10.1016/j.talanta.2007.10.030

[15] N. Yilmaz, S. A. Özkan, B. Uslu, Z. Sentürk and İ. Biryol, "Determination of Terbutaline Based on Oxidation by Voltammetry," Journal of Pharmaceutical and Biomedi- cal. Analysis, Vol. 17, No. 2, 1998, pp. 349-355. doi:10.1016/S0731-7085(97)00226-4

[16] S. Iijima, "Helical Microtubules of Graphitic Carbon," Nature, Vol. 354, No. 6348, 1991, pp. 56-58. doi: $10.1038 / 354056 \mathrm{a} 0$

[17] E. Katz, I. Willner and J. Wang, "Electroanalytical and Bioelectroanalytical Systems Based on Metal and Semiconductor Nanoparticles," Electroanalysis, Vol. 16, No. 1-2, 2004, pp. 19-44. doi:10.1002/elan.200302930

[18] H. Xiong, Y. Zhao, P. Liu, X. Zhang and S. Wang, "Electrochemical Properties and the Determination of Nicotine at a Multi-Walled Carbon Nanotubes Modified Glassy Carbon Electrode," Microchimica Acta, Vol. 168, No. 1-2, 2010, pp. 31-36. doi:10.1007/s00604-009-0258-8

[19] C. M. Welch and R. G. Compton, "The Use of Nanoparticles in Electroanalysis: A Review," Analytical and Bioanalytical Chemistry, Vol. 384, No. 3, 2006, pp. 601-619. doi:10.1007/s00216-005-0230-3

[20] A.Y. Kasumov, H. Bouchiat, B. Reulet, O. Stephan, I. Khodos, Y. B. Gorbatov and C. Colliex, "Conductivity and Atomic Structure of Isolated Multiwalled Carbon Nanotubes," Europhysics Letters, Vol. 43, No. 1, 1998 , pp. 89-94. doi:10.1209/epl/i1998-00324-1

[21] A. J. Bard and L. R. Faulkner, "Electrochemical Methods," 2nd Edition, Wiley, New York, 2001.

[22] S. Shahrokhian and L. Fotouhi, "Carbon Paste Electrode Incorporating Multi-Walled Carbon Nanotube/Cobalt Salophen for Sensitive Voltammetric Determination of Tryptophan," Sensors and Actuators B: Chemical, Vol. 123, No. 2, 2007, pp. 942-949. doi:10.1016/j.snb.2006.10.053

[23] Y. Liu, Z. Shen and K. Yokogawa, "Investigation of Preparation and Structures of Activated Carbon Nanotubes," Materials Research Bulletin, Vol. 41, No. 8, 2006 , pp. 1503-1512. doi:10.1016/j.materresbull.2006.01.017

[24] A. M. Bond, "Modern Polarographic Methods," In: M. Dekker, Ed., Analytical Chemistry, 1980, p. 29. 